\title{
Achalasia Is Associated With eNOS4a4a, iNOS22GA, and nNOS29TT Genotypes: A Case-control Study
}

\author{
Rajan Singh, ${ }^{1}$ Uday C Ghoshal, ${ }^{1 *}$ Asha Misra, ${ }^{1}$ and Balraj Mittal ${ }^{2}$ \\ Departments of ${ }^{1}$ Gastroenterology and ${ }^{2}$ Medical Genetics, Sanjay Gandhi Postgraduate Institute of Medical Sciences, Lucknow, India
}

\begin{abstract}
Background/Aims
Achalasia is known to result from degeneration of inhibitory neurons, which are mostly nitrinergic. Characteristic features of achalasia include incomplete lower esophageal sphincter (LES) relaxation and esophageal aperistalsis. Nitric oxide (NO), produced by NO synthase (NOS), plays an important role in peristalsis and LES relaxation. Therefore, we evaluated genetic polymorphisms of NOS gene isoforms (endothelial NOS [eNOS], inducible NOS [iNOS], and neuronal NOS [nNOS]) in patients with achalasia and healthy subjects (HS).
\end{abstract}

\section{Methods}

Consecutive patients with achalasia (diagnosed using esophageal manometry) and HS were genotyped for 27-base pair (bp) eNOS variable number of tandem repeats (VNTR), iNOS22G/A (rs1060826), nNOS C/T (rs2682826) polymorphisms by polymerase chain reaction (PCR) and PCR-restriction fragment length polymorphism (RFLP), respectively.

\section{Results}

Among 183 patients (118 [64.5\%] male, age $39.5 \pm 13.0$ years) with achalasia and 366 HS (254 [69.4\%] male, age $40.8 \pm$ 11.0 years), eNOS4a4a genotype of 27-bp VNTR was more common among achalasia than HS (20 [10.9\%] vs 13 [3.6\%]; P $<0.001 ; O R, 3.72 ; 95 \% \mathrm{Cl}, 1.8-7.7)$. Patients with achalasia had iNOS22GA genotypes more often than HS (95 [51.9\%] vs $\left.93[25.4 \%] ; P<0.001 ; O R, 3.0 ; 95 \% \mathrm{Cl}_{2} 2.1-4.4\right)$. Frequency of genotypes $\mathrm{GA}+\mathrm{AA}$ was higher in patients than HS (97 [53\%] vs 107 [29.2\%]; $P<0.001 ;$ OR, 2.7; 95\% Cl, 1.8-3.9). Also, nNOS29TT variant genotype in rs2682826 was more common among patients compared to HS (14 [7.7\%] vs $6[1.6 \%] ; P<0.001 ; \mathrm{OR}, 5.91 ; 95 \% \mathrm{Cl}, 2.2-15.8)$.

\section{Conclusions}

Achalasia is associated with eNOS4a4a, iNOS22GA, and nNOS29TT genotypes. This may suggest that polymorphisms of eNOS, iNOS, and nNOS genes are risk factors for achalasia.

(J Neurogastroenterol Motil 2015;21:380-389)

\section{Key Words}

Esophageal motility disorder; Genes; Motor dysphagia; Nitric oxide; Polymorphism

Received: December 27, 2014 Revised: January 25, 2015 Accepted: January 25, 2015

(c) This is an Open Access article distributed under the terms of the Creative Commons Attribution Non-Commercial License (http://creativecommons. org/licenses/by-nc/4.0) which permits unrestricted non-commercial use, distribution, and reproduction in any medium, provided the original work is properly cited.

*Correspondence: Uday C Ghoshal, MD, DNB, DM, FACG, RFF

Department of Gastroenterology, Sanjay Gandhi Post Graduate Institute of Medical Sciences, Lucknow 226014, India

Tel: +91-522-2494405, Fax: +91-522-2668017 or 2668078, E-mail: udayghoshal@gmail.com

Rajan Singh and Uday C Ghoshal both are the first authors of this paper.

Financial support: None.

Conflicts of interest: None.

Author contributions: Rajan Singh, data collection, molecular works, data analysis, and drafting of the manuscript; Uday C Ghoshal, study concept and design, contribution to planning and execution of the work, recruitment of patients, upper gastrointestinal endoscopy and esophageal manometry procedures, supervision of work, contribution to data analysis, and critical revision of the manuscript for important intellectual content; Asha Misra, technical assistance in esophageal manometry procedures; and Balraj Mittal, valuable input regarding the genetic analysis, supervision of molecular works, and manuscript editing.

ORCID: Uday C Ghoshal, http://orcid.org/0000-0003-0221-8495. 


\section{Introduction}

Achalasia is a common cause of motor dysphagia. ${ }^{1}$ Its pathogenesis is still enigmatic. ${ }^{2-4}$ Genetic factors are likely to be important in its pathogenesis as supported by occasional familial aggregation, concordance among monozygotic twins and reports on association between achalasia and Hirshsprung's disease, a similar condition with genetic basis. ${ }^{5-7}$ Esophageal aperistalsis and incomplete lower esophageal sphincter (LES) relaxation, the characteristic features of achalasia, result from degeneration of the ganglion cells in the myenteric plexus. ${ }^{8}$ Abnormal esophageal function in patients with achalasia is due to loss of inhibitory innervation. ${ }^{9}$

Nitric oxide (NO) is the most important inhibitory neurotransmitter of the esophageal myenteric plexus; it progressively delays muscular contraction in the distal esophagus preventing simultaneous contraction and relaxes LES during swallowing in healthy persons. ${ }^{3}$ Degeneration of NO-containing neurons, therefore, causes simultaneous contraction in the esophageal body and failure of swallow-induced LES relaxation. ${ }^{9,10} \mathrm{NO}$ is synthesized by NO synthase (NOS), which has 3 isoforms, namely, endothelial NOS (eNOS), inducible NOS (iNOS), and neuronal NOS (nNOS). ${ }^{11,12}$ The genes encoding for these isoforms are located in the human chromosomes 7q36, 17q11.2-q12, and, 12q24.2, respectively, which have several polymorphisms. ${ }^{11,13-19}$

Polymorphisms in eNOS, iNOS, and nNOS genes result in occurrence of either "high" or "low" producer alleles. Subjects homozygous for the high-producer alleles synthesize the highest amount of NO, those homozygous for the low-producer alleles the least, while heterozygotes produce an intermediate amount. ${ }^{13,20}$ In the 27-bp variable number of tandem repeats (VNTR) polymorphism, 2 alleles have been identified; the larger of which, eNOS-4b (higher-producer of NO), has 5 tandem 27-bp repeats (GAAGTCTAGACCTGCTGC [A/G] GGGGTGAG) and the smaller, eNOS-4a (lower-producer of NO), has 4 tandem 27-bp repeats. ${ }^{21}$ 27-bp VNTR polymorphism of eNOS is associated with a low plasma concentration of nitric oxide. ${ }^{22}$ The functional role of iNOS (G/A-37498) polymorphism is not well known but it may alter $\mathrm{NO}$ activity. ${ }^{16}$ The allelic variant of nNOS C/T in exon 29 is located in an untranslated region of the gene and may influence the rate of expression and stability of nNOS mRNA. ${ }^{23}$ Studies on the association between NOS gene isoform polymorphisms and achalasia, however, are scanty. In a study from Spain, a trend toward a higher prevalence of geno- types iNOS22AA and eNOS4a4a was found among patients with achalasia. ${ }^{11}$ However, the difference was not statistically significant. In another study from Spain, the frequency of iNOS22AA genotypes was lower among patients with achalasia than controls. ${ }^{24}$ Hence, studies on larger number of patients and controls are needed.

We hypothesized that low-producer polymorphisms of eNOS, iNOS, and nNOS gene may be associated with achalasia. Thus, we aimed to study host genetic polymorphisms of eNOS (27-bp-VNTR), iNOS22 (G/A-37498), and nNOS29 (C/T) genes in patients with achalasia as compared to healthy subjects (HS) and evaluated relationship between various sub-types of achalasia and genotypes.

\section{Materials and Methods}

\section{Study Participants}

\section{Sample size calculation}

Sample size was calculated using Quanto version 1.1.1. Sample size for eNOS 27-bp VNTR polymorphism was calculated according to the following parameters: significance level (2-tailed) 0.05 , odds ratio (OR) 2.0 , power of the study $80 \%$ and ratio of case to control equal to $1: 2$; proportion of population expected to have achalasia based on previous study of $0.01 \%$ and proportion of control expected to have eNOS " $4 \mathrm{a}$ " variant allele frequency of $23 \%$ as reported from India. ${ }^{13,25}$ The sample size was estimated to be 183 patients and 366 controls.

Sample size for iNOS gene G/A-37498 polymorphism was calculated keeping all the above-mentioned parameters same and variant " $\mathrm{A}$ " allele frequency of $41 \%$ among controls as reported from France. ${ }^{23}$ The sample size was estimated to be 145 patients and 290 controls.

Similarly, the sample size for $\mathrm{nNOS}$ gene $\mathrm{C} / \mathrm{T}$ polymorphism was calculated according to the above parameters and variant "T" allele frequency of $26 \%$ among control population as reported from Spain. ${ }^{11}$ The sample size was estimated to be $171 \mathrm{pa}-$ tients and 342 controls.

One hundred eighty-three patients with achalasia were included during a 5-year period (2008 to 2013). The diagnosis of achalasia was suspected on the basis of clinical, radiological, endoscopic parameters and confirmed on esophageal manometry (conventional or high resolution, HRM) according to the standard parameters. ${ }^{26-28}$ 
HS were invited from the community. A total of 366 age and gender-matched unrelated HS of similar ethnicity, free from any significant gastrointestinal symptoms were included as controls from the same population. All the patients and controls consented to participate in the study. The Institutional Ethics Committee approved the study protocol.

\section{Clinical Assessment}

Severity of dysphagia, regurgitation and chest pain was assessed according to the following scoring system: 0 , never; 1 , once per month; 2, once per week; 3, 2-4 times per week; 4, once per day; and 5, several times per day. Other symptoms like regurgitation, heartburn, globus sensation were also assessed.

\section{Esophageal Manometry}

From May 2008 till October 2010, patients underwent conventional manometry $(\mathrm{n}=96)$, From November 2010 till May 2013, HRM was performed $(n=87)$. Conventional esophageal manometry was performed using station and rapid pull-through methods by standard techniques. ${ }^{26}$ Esophageal HRM was performed using a water perfusion system (G S Hebbard system, Melbourne, Australia) and 16-ports catheter using standard technique. Manometry signals were analyzed using "Trace 1.2" software (G S Hebbard system), which was applied to the data tracings viewed as Clouse plot. Intra-gastric pressure was used as baseline for any pressure measurement.

\section{Diagnosis and Sub-typing of Achalasia}

Achalasia was diagnosed on conventional and HRM and sub-typed using standard criteria and Chicago classification, respectively. ${ }^{26,27,29}$ Body motility, distal contractile integral and integrated relaxation pressure (IRP) were evaluated in response to 10 water swallows (5 $\mathrm{mL}$ each) according to standard methods. ${ }^{27}$ Patients were classified either into classic or vigorous types with conventional manometry. ${ }^{29}$ On HRM, achalasia was classified into type I, type II, and type III as per Chicago classification. ${ }^{28}$ In the earlier classification, patients with achalasia with low amplitude contractions in the body (average amplitude $\leq 40 \mathrm{mmHg}$ ) were classified as classic achalasia. Those with high amplitude contractions in the esophageal body (average amplitude $>40 \mathrm{mmHg}$ ), either focal segmental or diffuse, were classified as vigorous achalasia. ${ }^{29}$ In the current Chicago classification, those with low amplitude contraction in the body as represented by no distal esophageal pressurization of $>30 \mathrm{mmHg}$ in $\geq 8$ of the 10 wet swallows are classified as type I, those with pan-esophageal pressurization to $>30 \mathrm{mmHg}$ in at least 2 out of the 10 wet swallows are classified as type II and those with preserved fragments of distal peristalsis or premature (spastic) contractions in 2 or more of the 10 swallows are classified as type III. $^{30}$ The value of IRP had to be $>10 \mathrm{mmHg}$ to diagnose type I and $>15 \mathrm{mmHg}$ to diagnose type II and III achalasia. ${ }^{31} \mathrm{We}$ grouped classic achalasia according to older classification and type I according to the current Chicago classification as low amplitude and vigorous achalasia according to the older classification and type II and III according to the newer classification as high amplitude achalasia for the purpose of our study.

\section{Sample Collection}

Genomic DNA, extracted from venous blood in ethylene di-amine tetra acetic acid (EDTA) using commercially available kit (Qiagen Inc, Valencia, CA, USA), was used to study NOS gene polymorphism.

\section{Quantitation and Storage of DNA}

The quality and purity of DNA was evaluated by the ratio of optical density (OD) at $260 \mathrm{~nm}$ and $280 \mathrm{~nm}$. The ratio of absorbance at 260 and $280 \mathrm{~nm}$ of DNA was around 1.7-1.9. Purity of DNA was also confirmed by $1 \%$ agarose gel electrophoresis in $1 \times$ TBE buffer.

\section{Genotyping of Endothelial Nitric Oxide Synthase Gene 27-base Pair Variable Number of Tandem Repeats Polymorphism}

Genotyping of eNOS gene 27-bp VNTR was determined using polymerase chain reaction (PCR). PCR amplification was carried out in a total volume of $25 \mu \mathrm{L}$ with $10 \mathrm{pmol}$ of forward and reverse primers. Forward primer was $5^{\prime}$-AGGCCCTATGGTAGTGCCTTT-3' and reverse was 5' ${ }^{\prime}$-TCTCTTAGTGCTGTGGTCA $-3^{\prime}$. The constituents of $\mathrm{PCR}$ reaction mixture contained 100-150 ng of genomic DNA, $1.5 \mathrm{mM} \mathrm{MgCl}_{2}, 20$ $\mathrm{mM}$ Tris- $\mathrm{HCl}$ ( $\mathrm{pH}$ 8.0), $50 \mathrm{mM} \mathrm{KCl}, 0.2 \mathrm{mM}$ each dNTP and 2.0 U of Taq DNA polymerase (Bangalore Genei, Bangalore, India). Protocol for PCR amplification was as follows: initial denaturation at $97^{\circ} \mathrm{C}$ for 5 minutes followed by 35 cycles of denaturation at $95^{\circ} \mathrm{C}$ for 1 minute, annealing at $55^{\circ} \mathrm{C}$ for 30 seconds, extension at $72^{\circ} \mathrm{C}$ for 1 minute, and 10 minutes of final extension at $72^{\circ} \mathrm{C}$. PCR products were separated on $3 \%$ agarose gels and visualized after ethidium bromide staining under ultraviolet trans-illumination. Two different alleles, denoted as allele $4 \mathrm{~b}$ (5 repeats) and $4 \mathrm{a}$ (4 repeats) were identified (Fig. 1A). ${ }^{11}$ 
A

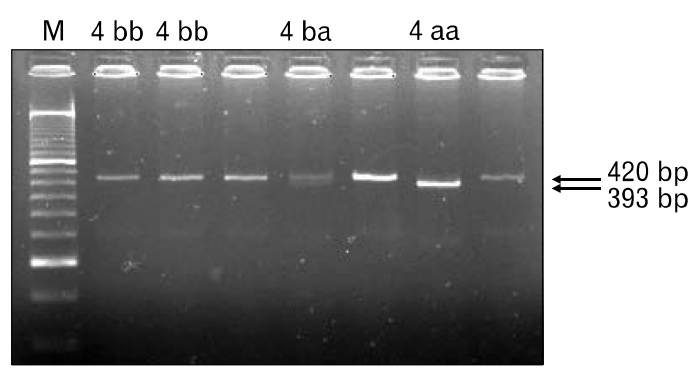

B

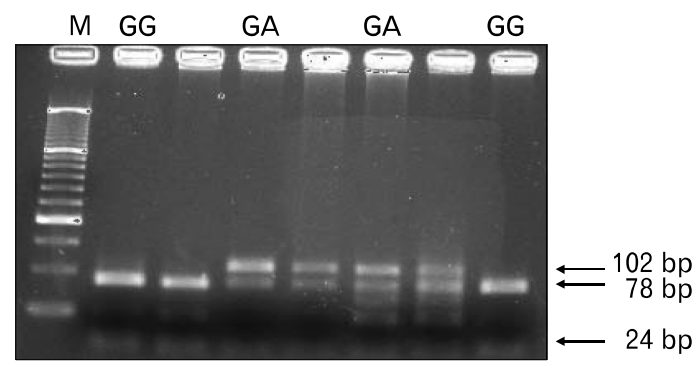

C

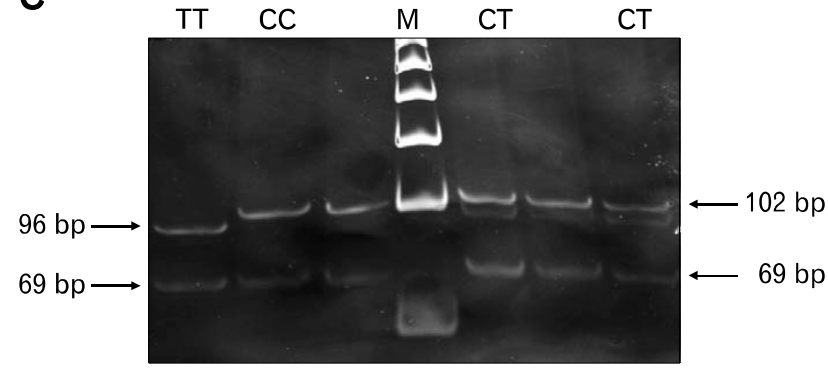

Figure 1. Representative gel pictures of 27-base pair (bp) variable number of tandem repeats of endothelial nitric oxide synthase (eNOS), inducible NOS (iNOS)22 G/A (rs1060826), and neuronal NOS (nNOS) C/T (rs2682826) polymorphisms. (A) Polymerase chain reaction (PCR) products of 27-bp VNTR of eNOS polymorphism were run on 3\% agarose gel electrophoresis (AGE): lanes 2-7 show various genotypes, lane 1 shows a 50-bp DNA ladder. (B) PCRrestriction fragment length polymorphism products of iNOS22 G/A (rs1060826) polymorphism were run on 3\% AGE: lanes 2-7 show various genotypes, lane 1 shows a 50-bp DNA ladder. (C) PCRrestriction fragment length polymorphism products of $\mathrm{nNOS} \mathrm{C} / \mathrm{T}$ (rs2682826) polymorphism were run on $15 \%$ polyacrylamide gel electrophoresis (PAGE): lanes 1-3 and 5-6 show various genotypes, lane 4 show a 50-bp DNA ladder.

\section{Genotyping of Inducible Nitric Oxide Synthase Gene G/A-37498 Polymorphism}

Genotyping of iNOS gene G/A (rs1060826) was determined using PCR followed by restriction digestion. PCR amplification was carried out in a total volume of $25 \mu \mathrm{L}$ with 10 pmol of forward and reverse primers. Forward primer used was 5 '-CTGCTGGCTTCCTGCTTTCC-3' and reverse primer was 5'-CTC-
GGGTGTGGTAGGTGACC-3'. Genomic DNA (100-150 ng), $1 \times 500 \mathrm{mM} \mathrm{KCl}$ buffer $(\mathrm{pH} 8.4), 5 \mathrm{mM} \mathrm{MgCl} 2,0.2 \mathrm{mM}$ dNTP set, and 1 U Taq DNA polymerase (Bangalore Genei) were used in the PCR reaction mixture. Protocol for PCR amplification was as follows: initial denaturation at $95^{\circ} \mathrm{C}$ for 10 minutes followed by 34 cycles of denaturation at $95^{\circ} \mathrm{C}$ for 1 minute, annealing at $66^{\circ} \mathrm{C}$ for 30 seconds and extension at $72^{\circ} \mathrm{C}$ for 30 seconds. The final extension at $72^{\circ} \mathrm{C}$ was for 10 minutes. The PCR product was digested with restriction enzyme Btg (10 $\mathrm{U} / \mu \mathrm{L}, \mathrm{NEB}$ ) at $37^{\circ} \mathrm{C}$ overnight and fragments were analyzed on $3 \%$ agarose gels stained with ethidium bromide. The $\mathrm{G}$ allele was defined by the presence of 3 fragments of 78, 24, and $24 \mathrm{bp}$ and the $\mathrm{A}$ allele by the presence of 2 fragments of $102 \mathrm{bp}$ and $24 \mathrm{bp}$ (Fig. 1B). ${ }^{11}$

\section{Genotyping of Neuronal Nitric Oxide Synthase Gene C/T Polymorphism}

Genotyping of nNOS29 gene C/T (rs2682826) was determined using PCR followed by restriction digestion. PCR amplification was carried out in a total volume of $25 \mu \mathrm{L}$ with 10 pmol of forward and reverse primers. Forward primer used was 5'-TTGAGTTTTCCTGCTGCGATGT-3' and reverse primer was 5'-GCTTGTGCCTAGTTCCTGCA-3'. Genomic DNA (100-150 ng), $1 \times 500 \mathrm{mM} \mathrm{KCl}$ buffer (pH 8.4), $5 \mathrm{mM}$ $\mathrm{MgCl}_{2}, 0.2 \mathrm{mM} \mathrm{dNTP}$ set, and $1 \mathrm{U}$ Taq DNA polymerase (Bangalore Genei) were used in the PCR reaction mixture. PCR amplification was performed as follows: initial denaturation at $95^{\circ} \mathrm{C}$ for 6 minutes followed by 34 cycles of denaturation at $95^{\circ} \mathrm{C}$ for 1 minute, annealing at $68^{\circ} \mathrm{C}$ for 30 seconds and extension at $72^{\circ} \mathrm{C}$ for 30 seconds. The final extension at $72^{\circ} \mathrm{C}$ was for 10 minutes. The PCR product was digested with restriction enzyme NlaIII (5 U/ $\mu \mathrm{L}$; New England Biolabs, Frankfurt, Germany) at $37^{\circ} \mathrm{C}$ overnight and fragments were analyzed on $15 \%$ polyacrylamide gels stained with ethidium bromide. The $\mathrm{C}$ allele was defined by the presence of 3 fragments of 102, 69, and 16 bp and the $\mathrm{T}$ allele by the presence of 4 fragments of $94,69,16$, and $8 \mathrm{bp}$ (Fig. 1C). ${ }^{23}$

\section{Statistical Methods}

Differences in genotype frequency in patients with achalasia and HS were compared using $2 \times 2$ contingency table using $\chi 2$ test with Yates' correction, as applicable. The direct gene counting method was used to determine the frequency of genotypes. The $\chi 2$ goodness of fit test was used to check for any deviation from Hardy-Weinberg equilibrium in HS. Continuous data 
were analyzed using unpaired $t$ test. $P$-values less than 0.05 were considered significant. The association between NOS gene polymorphisms and achalasia were analyzed using binary logistic regression. The OR was adjusted for confounding factors such as age and gender. Data were analyzed using the statistical software SPSS, version 15.0 (SPSS Inc, Chicago, IL, USA).

\section{Results}

\section{Gender and Age of the Study-participants}

Patients with achalasia $(n=183 ; 39.5 \pm 13.0$ years; 118 [64.5\%] male) were comparable with HS ( $\mathrm{n}=366 ; 40.8 \pm 11.0$ years; 254 [69.4\%] male) with respect to age and gender and all were unrelated natives from northern India. None of HS had dysphagia, significant regurgitation (more than twice per week) or chest pain. None had any functional gastrointestinal disease as

Table 1. Demographic, Clinical, and Manometric Characteristics of Patients With Achalasia

\begin{tabular}{lc}
\hline Parameters & $\begin{array}{c}\text { Patients with } \\
\text { achalasia }(\mathrm{n}=183)\end{array}$ \\
\hline Age (mean $\pm \mathrm{SD}, \mathrm{yr})$ & $39.5 \pm 13.0$ \\
Gender (Male, $\mathrm{n}[\%])$ & $118(64.5)$ \\
Dysphagia (n [\%]) & $183(100.0)$ \\
Regurgitation more than twice per week (n [\%]) & $119(65.0)$ \\
Bolus obstruction (n [\%]) & $65(35.5)$ \\
Globus sensation (n [\%]) & $86(47.0)$ \\
Nasal regurgitation (n [\%]) & $113(61.7)$ \\
Heartburn (n [\%]) & $49(26.8)$ \\
Chest pain (n [\%]) & $93(50.8)$ \\
Cough (n [\%]) & $89(48.6)$ \\
Weight loss (n [\%]) & $121(66.1)$ \\
Dysphagia duration (mean $\pm \mathrm{SD}, \mathrm{mo})$ & $41.6 \pm 50.0$ \\
LES pressure (mean $\pm \mathrm{SD}, \mathrm{mmHg})$ & $38.5 \pm 18.7$ \\
DCI (median [range], mmHg $\cdot \mathrm{sec} \cdot \mathrm{cm})$ & $1139(0-10750)$ \\
IRP (mean \pm SD, mmHg) & $35.3 \pm 20.0$ \\
Maximum distal esophageal pressure & $44.8 \pm 27.0$ \\
(mean \pm SD, mmHg) & \\
Sub-types of achalasia & $104(56.8)$ \\
Low-amplitude achalasia & $79(43.2)$ \\
High-amplitude achalasia &
\end{tabular}

SD, standard deviation; LES, lower esophageal sphincter; DCI, distal contractile integral; IRP, integrated relaxation pressure; Low-amplitude achalasia, classic and type I achalasia; High-amplitude achalasia, vigorous and type II + type III achalasia.

DCI and IRP was calculated only in patients with achalasia undergoing high-resolution manometry. defined by Rome III criteria. ${ }^{32}$ In HS, the frequency of genotypes was in Hardy-Weinberg equilibrium.

\section{Clinical Parameters and Characterization of Phenotype}

All the 183 patients with achalasia had daily dysphagia of long duration (41.6 \pm 50.0 months). Median severity score for symptoms such as dysphagia, regurgitation and chest pain was 5.0 (range: 1-5), $3.0(0-5)$ and $1.0(0-5)$, respectively. Some patients also reported nasal regurgitation and bolus obstruction (Table 1). On upper gastrointestinal endoscopy, findings included: tight LES ( $\mathrm{n}=26$ [14.2\%]), dilated body of the esophagus $(\mathrm{n}=30[16.4 \%])$, tight $\mathrm{LES}$ as well as dilated body $(\mathrm{n}=$ $23[12.6 \%])$, excess food residue ( $\mathrm{n}=4$ [2.2\%]), dilated body with food residue ( $\mathrm{n}=47$ [25.7\%]), and normal $(\mathrm{n}=53$ [29\%]). Barium esophagogram revealed: dilated body of the esophagus ( $\mathrm{n}=16[8.7 \%])$, bird beaking of the lower end $(\mathrm{n}=$ $50[27.3 \%])$, dilated body with bird beaking $(\mathrm{n}=92[50.3 \%])$, and normal study ( $\mathrm{n}=25[13.7 \%])$.

\section{Sub-types of Achalasia}

On conventional esophageal manometry (done in 96 patients), 74 had classic and 22 had vigorous achalasia. On HRM (done in 87 patients), 30, 56, and 1 had type I, type II, and type III achalasia, respectively using Chicago classification. ${ }^{27}$ For the purpose of analysis, classic achalasia was grouped with type I (74 $+30=104$, referred as low-amplitude achalasia) and vigorous with type II and III $(22+56+1=79$, referred as high-amplitude achalasia).

\section{Manometry Parameters}

Patients with type I achalasia had lower basal LES pressure (Fig. 2A) compared to other sub-types. Type I achalasia had lower distal contractile integral and IRP than other sub-types (Fig. $2 \mathrm{~B}$ and 2C). Maximum esophageal pressurization (values plotted are the means for each patient at whatever location along the distal segment the pressure was highest) during the 10 test swallows was lower among type I achalasia than other sub-types (Fig. 2D).

\section{Result of Endothelial Nitric Oxide Synthase 27-base Pair Variable Number of Tandem Repeats Polymorphism}

The genotype distribution in patients with achalasia and HS are shown in Table 2. Patients with achalasia had a higher frequency of eNOS4a4a genotype (lower-producer of NO) of 
A

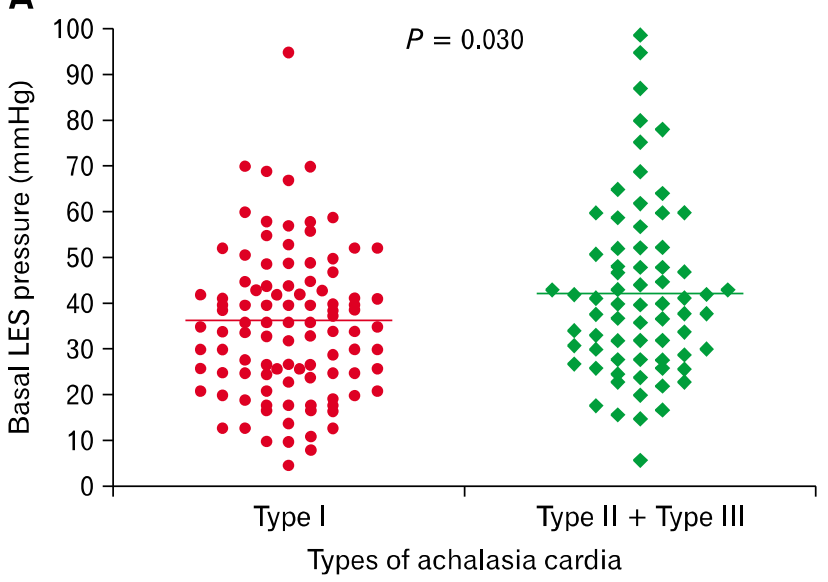

C

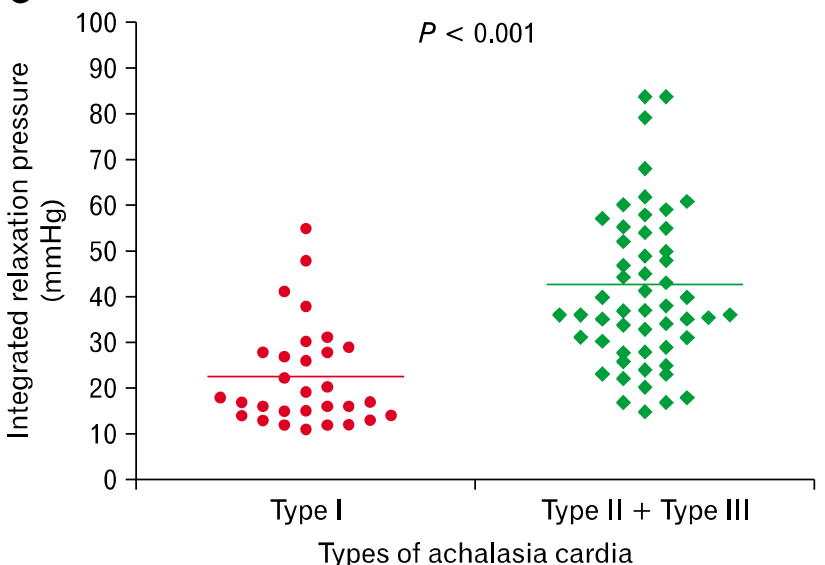

B

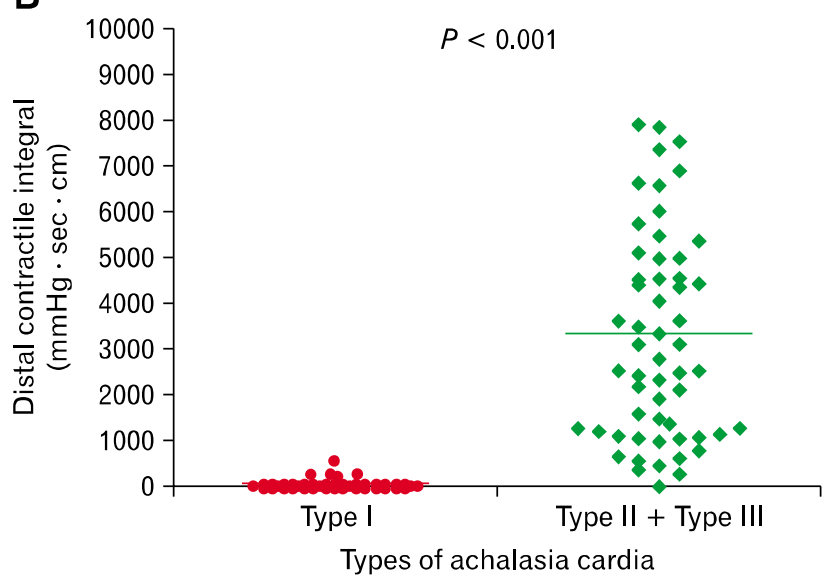

D

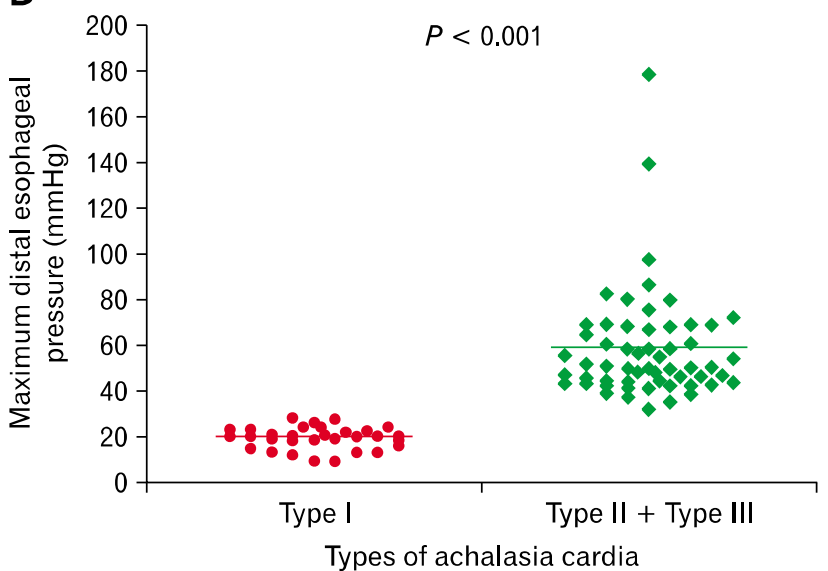

Figure 2. Comparison of manometric parameters among patients with achalasia. (A) Basal lower esophageal sphincter (LES) pressure (mmHg). (B) Distal contractile integral (DCI, $\mathrm{mmHg} \cdot \mathrm{sec} \cdot \mathrm{cm}$ ). (C) Integrated relaxation pressure (IRP, $\mathrm{mmHg}$ ). (D) Maximum distal esophageal pressure (mmHg). DCI and IRP was calculated only in patients with achalasia undergoing high-resolution manometry.

Table 2. Genotype Frequency of Endothelial Nitric Oxide Synthase 27-bp Variable Number of Tandem Repeats Gene Polymorphism in Patients With Achalasia and Healthy Subjects

\begin{tabular}{lcccc}
\hline Genotypes & $\begin{array}{c}\text { Patients with } \\
\text { achalasia } \mathrm{N}^{\mathrm{a}}(\%)\end{array}$ & $\begin{array}{c}\text { HS } \\
\mathrm{N}^{\mathrm{a}}(\%)\end{array}$ & $\begin{array}{l}\text { P-value } \\
\text { OR (95\% CI) }\end{array}$ & $\begin{array}{c}\text { Reference } \\
\text { eNOS4b4b (higher-producer of NO) }\end{array}$ \\
\hline $111(60.7)$ & $269(73.5)$ & - & $1.50(0.99-2.20)$ \\
eNOS4b4a (intermediate-producer of NO) & $52(28.4)$ & $84(23.0)$ & 0.053 & $3.72(1.80-7.70)$ \\
eNOS4a4a (lower-producer of NO) & $20(10.9)$ & $13(3.6)$ & $<0.001$ & \\
\hline
\end{tabular}

${ }^{\mathrm{a}}$ Total number of patients with achalasia (183) and healthy subjects (366).

HS, healthy subjects; OR, odds ratio; CI, confidence interval; eNOS, endothelial nitric oxide synthase; NO, nitric oxide.

Statistical test: binary logistic regression model was used to calculate age and gender adjusted OR and 95\% CI.

27-bp VNTR than HS (20 [10.9\%] vs $13[3.6 \%], P<0.001)$. However, frequency of other genotypes ie, eNOS4b4a (intermediate-producer of $\mathrm{NO}$ ) and 4b4b (higher-producer of NO) was similar among patients and HS. Subjects having eNOS4a4a genotypes (lower-producer of NO), were significant- ly associated with achalasia (OR, 3.72; 95\% CI, 1.8-7.7; $P<$ $0.001)$. 
Table 3. Genotype Frequency of Inducible Nitric Oxide Synthase G/A-37498 Gene Polymorphism in Patients With Achalasia and Healthy Subjects

\begin{tabular}{lcccc}
\hline Genotypes & $\begin{array}{c}\text { Patients with } \\
\text { achalasia N } \mathrm{N}^{\mathrm{a}}(\%)\end{array}$ & $\begin{array}{c}\mathrm{HS} \\
\mathrm{N}^{\mathrm{a}}(\%)\end{array}$ & $\begin{array}{l}\text {-value } \\
\text { OR (95\% CI) }\end{array}$ \\
\hline iNOS22GG (wild genotype) & $86(47.0)$ & $259(70.8)$ & - & Reference \\
iNOS22GA (heterozygous genotype) & $95(51.9)$ & $93(25.4)$ & $<0.001$ & $3.00(2.10-4.40)$ \\
iNOS22AA (variant genotype) & $2(1.1)$ & $14(3.8)$ & 0.270 & $0.43(0.10-1.90)$ \\
\hline
\end{tabular}

${ }^{a}$ Total number of patients with achalasia (183) and healthy subjects (366).

HS, healthy subjects; OR, odds ratio; CI, confidence interval; iNOS, inducible nitric oxide synthase.

Statistical test: binary logistic regression model was used to calculate age and gender adjusted OR and 95\% CI.

Table 4. Genotype Frequency of Inducible Nitric Oxide Synthase G/A-37498 Gene Polymorphism (Dominant Model) in Patients With Achalasia and Healthy Subjects

\begin{tabular}{lcccc}
\hline Genotypes & $\begin{array}{c}\text { Patients with } \\
\text { achalasia } \mathrm{N}^{\mathrm{a}}(\%)\end{array}$ & $\begin{array}{c}\mathrm{HS} \\
\mathrm{N}^{\mathrm{a}}(\%)\end{array}$ & $P$-value & OR (95\% CI) \\
\hline $\begin{array}{l}\text { iNOS22GG (wild genotype) } \\
\text { iNOS22GA + AA }\end{array}$ & $86(47.0)$ & $259(70.8)$ & - & Reference \\
$\quad$ (Heterozygous + Homozygous variant genotypes) & $97=95+2(53.0)$ & $107=93+14(29.2)$ & $<0.001$ & $2.70(1.80-3.90)$ \\
\hline
\end{tabular}

${ }^{\mathrm{a}}$ Total number of patients with achalasia (183) and healthy subjects (366).

HS, healthy subjects; OR, odds ratio; CI, confidence interval; iNOS, inducible nitric oxide synthase.

Statistical test: binary logistic regression model was used to calculate age and gender adjusted OR and 95\% CI.

Table 5. Genotype Frequency of Neuronal Nitric Oxide Synthase29 C/T Gene Polymorphism in Patients With Achalasia and Healthy Subjects

\begin{tabular}{lcccc}
\hline Genotypes & $\begin{array}{c}\text { Patients with } \\
\text { achalasia N } \mathrm{N}^{\mathrm{a}}(\%)\end{array}$ & $\begin{array}{c}\text { HS } \\
\mathrm{N}^{\mathrm{a}}(\%)\end{array}$ & $P$-value & OR (95\% CI) \\
\hline nNOS29CC (wild genotype) & $97(53.0)$ & $246(67.2)$ & - & Reference \\
nNOS29CT (heterozygous genotype) & $72(39.3)$ & $114(31.1)$ & 0.140 & $1.60(1.00-2.30)$ \\
nNOS29TT (variant genotype) & $14(7.7)$ & $6(1.6)$ & $<0.001$ & $5.90(2.20-15.80)$ \\
\hline
\end{tabular}

${ }^{\mathrm{a}}$ Total number of patients with achalasia (183) and healthy subjects (366).

HS, healthy subjects; OR, odds ratio; CI, confidence interval; nNOS, neuronal nitric oxide synthase.

Statistical test: binary logistic regression model was used to calculate age and gender adjusted OR and $95 \% \mathrm{CI}$.

\section{Result of Inducible Nitric Oxide Synthase Gene G/A (rs1060826) Polymorphism}

Patients with achalasia had more often iNOS22GA genotypes than HS (95 [51.9\%] vs 68 [25.4\%], $P<0.001$ ) (Table 3). Risk estimates were also calculated for a dominant genetic model using the most common homozygous genotype as reference and assuming iNOS22 "A" allele as the high risk allele. On applying dominant model (GG vs GA + AA), iNOS22G/A polymorphism was associated with achalasia $(\mathrm{OR}, 2.7 ; 95 \% \mathrm{CI}$, 1.8-3.9; $P<0.001$ ) (Table 4).

\section{Result of Neuronal Nitric Oxide Synthase Gene C/T (rs2682826) Polymorphism}

Patients with achalasia had more often nNOS29TT geno- types than HS (14 [7.7\%] vs $6[1.6 \%], P<0.001)$. However, frequency of other genotypes ie, $\mathrm{CC}$ and $\mathrm{CT}$ were similar in patients and HS (Table 5). Subjects having nNOS29TT genotypes were more often associated with achalasia than nNOS29CT and nNOS29CC (OR, 5.91; 95\% CI, 2.2-15.8; $P<0.001)$.

\section{Endothelial Nitric Oxide Synthase 27-bp Variable Number of Tandem Repeats, Inducible Nitric Oxide Synthase 22G/A, and Neuronal Nitric Oxide Synthase 29C/T Polymorphism in Various Sub-types of Achalasia}

Frequency of eNOS 27-bp VNTR polymorphism was comparable among patients with low- and high-amplitude achalasia (genotypes: eNOS4b4b 62/104 [59.6\%], 4b4a 31/104 [29.8\%], 
4a4a $11 / 104$ [10.6\%] vs 4b4b 49/79 [62.0\%], 4b4a 21/79 [26.6\%], 4a4a 9/79 [11.4\%]; $P=0.940)$. Similarly, frequency of iNOS G/A-37498 polymorphism was comparable among various sub-types of achalasia (genotypes: iNOS22GG 47/104 [45.2\%], GA 56/104 [53.8\%], AA 1/104 [1\%] among patients with low-amplitude achalasia vs GG 39/79 [49.4\%], GA 39/79 [49.4\%], AA 1/79 [1.3\%] among patients with high-amplitude achalasia; $P=0.890$ ). Also, $\mathrm{nNOS} 29 \mathrm{C} / \mathrm{T}$ polymorphism was comparable among various sub-types of achalasia (genotypes: nNOS29CC 54/104 [51.9\%], CT 42/104 [40.4\%], TT 8/104 [7.7\%] among patients with low-amplitude achalasia vs CC 43/79 [54.4\%], CT 30/79 [38\%], TT 6/79 [7.6\%] among patients with high-amplitude achalasia; $P=0.910$ ).

\section{Discussion}

The present study on a large number of patients with achalasia and HS showed that, eNOS4a4a genotype of 27-bp VNTR, iNOS22GA genotypes, and nNOS29TT variant genotype in rs2682826 were more common among patients with achalasia than HS. Moreover, on applying a dominant model, (GG vs GA + AA), iNOS22 G/A polymorphism was associated with achalasia. However, there was no relationship between these genotypes and various sub-types of achalasia.

Imbalance between inhibitory and excitatory neurons may lead to achalasia. ${ }^{3}$ Earlier, it was thought that inhibitory neurons were dopaminergic and VIP-ergic; several landmark studies reported subsequently, however, demonstrated that most inhibitory neurons were nitrinergic. ${ }^{433,34}$ Achalasia is known to result from degeneration of these inhibitory neurones, which are mostly nitrinergics. ${ }^{35-37}$ In this study, we examined whether degeneration of inhibitory neurones, mostly nitrinergic, may be associated with polymorhism in NOS gene. NOS gene have several polymorphisms such as 27-bp VNTR polymorphism of eNOS, a biallelic polymorphism in exon 16 of iNOS gene and in exon 29 of nNOS. The presence of these polymorphisms within NOS gene isoforms may influence the expression and activity of NOS and may result in variation in NO production. A few studies showed these polymorphisms to be associated with Parkinson's disease, migraines and cardiovascular disease..$^{22,23,38}$ In different studies, it has been shown that in patients with achalasia, the LES has less NOS as compared to controls. ${ }^{9}$ Studies in animals have shown that esophageal peristalsis and LES relaxation are normally controlled by NO. ${ }^{9,39,40}$ Also, knockout mice lacking nNOS exhibit a hypertonic LES with impaired relaxation on swallowing similar to that observed in achalasia patients. ${ }^{36}$ These observations could explain our results showing association between eNOS, iNOS, and nNOS gene polymorphisms and achalasia.

Our study showed that eNOS4a4a genotype of 27-bp VNTR polymorphism was associated with achalasia as compared with the presence of eNOS4b4b genotype. A previous case-control study by Mearin et $\mathrm{al}^{11}$ showed that the frequency of 27-bp VNTR polymorphism was comparable between patients with achalasia and HS. However, the sample size of patients and controls was small in that study; hence, a possibility of type II statistical error is quite likely. In 27-bp VNTR polymorphism of e-NOS, 4a allele has been associated with reduced plasma NO levels. Subjects homozygous for 4a allele exhibit 20\% lower levels of NO than the subjects bearing $4 \mathrm{~b}$ allele. ${ }^{21}$ Therefore, patients with achalasia having eNOS4a4a genotype would produce less amount of NO, leading to simultaneous contraction in the esophageal body and failure of swallow-induced LES relaxation. ${ }^{3}$ Thus, our finding showing association between achalasia and presence of eNOS4a4a genotype is important as this genotype is associated with low levels of NO, which is known to have role in development of achalasia.

Our data showed a difference in genotype frequency of iNOS22 G/A polymorphism between patients with achalasia and HS. Since the number of patients with homozygous AA genotype was small, we constructed a dominant model (GG vs GA + AA) to see the effect of "A" allele on the risk of development of achalasia. Our data showed that presence of " $A$ " allele carrier genotype (iNOS22GA and AA) was associated with achalasia. The functional role of iNOS22 G/A polymorphism is not clearly known. ${ }^{23}$ As the results of our study suggest that it might be associated with achalasia, it is possible that that these genes are in linkage disequilibrium with other genes, which might be associated with degeneration of inhibitory neurons. ${ }^{41}$ In contrast to our study, previous studies by Mearin et $\mathrm{al}^{11}$ and Vigo et $\mathrm{al}^{24}$ showed that iNOS22 G/A polymorphism was comparable between patients with achalasia and HS. However, they did not construct dominant model; moreover, sample size in those studies was smaller than that in our study. More studies are needed on this issue.

Our study showed that nNOS29TT genotype of nNOS29 $\mathrm{C} / \mathrm{T}$ polymorphism was associated with achalasia as compared with the presence of nNOS29CC genotype. The functional role of $\mathrm{nNOS} 29 \mathrm{C} / \mathrm{T}$ polymorphism is not clearly known. However, the importance of this gene as a risk factor for various neurodegenerative diseases such as schizophrenia, Parkinson's disease, 
fronto temporal lobar degeneration, suicidal behavior, and Alzheimer's disease has been established by association studies. ${ }^{20,23,42,43}$ These studies verified a higher risk of disease susceptibility with the $\mathrm{T}$ allele of nNOS29 C/T polymorphism. Achalasia is also a neurodegenerative disease not only confined to esophagus but also extended to brain as evidenced by Wallerian degeneration of vagus nerve, presence of Lewy bodies in the brainstem, impaired autonomic response to insulin-induced hypoglycemia, rare reports of association with other neuronal diseases such as Hirschsprung's disease, intestinal pseudo-obstruction and gastroparesis. ${ }^{44-46}$ Hence, it is logical to think that nNOS29 C/T polymorphism would be associated with achalasia. However, data on this issue is scanty. In a small case-control study reported till date, nNOS29 $\mathrm{C} / \mathrm{T}$ polymorphism was comparable among patients with achalasia and HS. ${ }^{11}$ Our study, however, contradicts that study and showed that the presence of nNOS29TT genotype was associated with achalasia.

We compared eNOS 27-bp VNTR, iNOS G/A-37498, and nNOS29 C/T polymorphisms in different sub-types of achalasia. There was no difference in frequency of these polymorphisms in low and high-amplitude achalasia. This is not entirely unexpected. In the early phase of achalasia, though there is degeneration of inhibitory neurons such as nitrinergic neuron, cholinergic system remains intact and therefore, the amplitude of esophageal contraction is high though these are simultaneous. In the later phase, degeneration of cholinergic system leads to reduced amplitude of contraction. ${ }^{3,33}$ In fact, this is the basis for combining patients with classic achalasia on conventional manometry with type I achalasia on HRM. Hence, genotypes are not expected to be different in sub-types of achalasia. In addition, when the association analysis was undertaken considering age as discriminating factor, our study showed no association between age of onset of the disease and NOSs gene polymorphisms. However, in the study by Paladini et al, ${ }^{47}$ only late onset achalasia was associated with VIPR1 gene polymorphisms (rs437876 and rs896).

A large sample size of patients and control was the strength of the study. The power of this sample size was $80 \%$ (probability of not making a type II error) to detect the risk of 1.5 or higher. However, there are some limitations of our study. We did not study the expression and/or activity of the NOSs enzymes. More studies with functional profiling of RNA may strengthen our hypothesis. We did not perform manometry among HS to rule out achalasia. However, since none of our patients had symptoms such as dysphagia, significant regurgitation and chest pain and achalasia is hardly ever asymptomatic, ${ }^{48}$ we believe that this is not a major limitation of our study. Moreover, performing manometry in such a large sample of HS was not ethically justified. Our findings may be population specific. Therefore, before generalizing the result to other population, more studies are needed validating this hypothesis in other population. In conclusion, our study suggests that eNOS4a4a, iNOS22 (GA + AA) and nNOS29TT genotypes are associated with achalasia. This study, therefore, provides support for genetic factors contributing to the pathogenesis of achalasia. However, the genetic factors may not play much role in development of various sub-types of achalasia.

\section{References}

1. Richter JE. Achalasia - an update. J Neurogastroenterol Motil 2010; $16: 232-242$.

2. Mittal RK, Hong SJ, Bhargava V. Longitudinal muscle dysfunction in achalasia esophagus and its relevance. J Neurogastroenterol Motil 2013;19:126-136.

3. Ghoshal UC, Daschakraborty SB, Singh R. Pathogenesis of achalasia cardia. World J Gastroenterol 2012;18:3050-3057.

4. Park W, Vaezi MF. Etiology and pathogenesis of achalasia: the current understanding. Am J Gastroenterol 2005;100:1404-1414.

5. Gockel HR, Schumacher J, Gockel I, Lang H, Haaf T, Nöthen MM. Achalasia: will genetic studies provide insights? Hum Genet 2010;128:353-364.

6. Stein DT, Knauer CM. Achalasia in monozygotic twins. Dig Dis Sci 1982;27:636-640.

7. Tryhus MR, Davis M, Griffith JK, Ablin DS, Gogel HK. Familial achalasia in two siblings: significance of possible hereditary role. $\mathrm{J}$ Pediatr Surg 1989;24:292-295.

8. De Giorgio R, Di Simone MP, Stanghellini V, et al. Esophageal and gastric nitric oxide synthesizing innervation in primary achalasia. Am J Gastroenterol 1999;94:2357-2362.

9. Mearin F, Mourelle M, Guarner F, et al. Patients with achalasia lack nitric oxide synthase in the gastro-oesophageal junction. Eur J Clin Invest 1993;23:724-728.

10. Konturek JW, Thor P, Lukaszyk A, Gabryelewicz A, Konturek SJ, Domschke W. Endogenous nitric oxide in the control of esophageal motility in humans. J Physiol Pharmacol 1997;48:201-209.

11. Mearin F, García-González MA, Strunk M, Zárate N, Malagelada JR, Lanas A. Association between achalasia and nitric oxide synthase gene polymorphisms. Am J Gastroenterol 2006;101:1979-1984.

12. Förstermann U, Sessa WC. Nitric oxide synthases: regulation and function. Eur Heart J 2012;33:829-837, 837a-837d.

13. Parveen F, Faridi RM, Alam S, Agrawal S. Genetic analysis of eNOS gene polymorphisms in association with recurrent miscarriage among North Indian women. Reprod Biomed Online 2011;23: 124-131.

14. Korhonen R, Lahti A, Kankaanranta H, Moilanen E. Nitric oxide production and signaling in inflammation. Curr Drug Targets Inflamm Allergy 2005;4:471-479.

15. Zamora R, Vodovotz Y, Billiar TR. Inducible nitric oxide synthase 
and inflammatory diseases. Mol Med 2000;6:347-373.

16. Qidwai T, Jamal F. Inducible nitric oxide synthase (iNOS) gene polymorphism and disease prevalence. Scand J Immunol 2010;72: 375-387.

17. Hall AV, Antoniou H, Wang Y, et al. Structural organization of the human neuronal nitric oxide synthase gene (NOS1). J Biol Chem 1994;269:33082-33090.

18. Miyahara K, Kawamoto T, Sase K, et al. Cloning and structural characterization of the human endothelial nitric-oxide-synthase gene. Eur J Biochem 1994;223:719-726.

19. Dellamea BS, Leitão CB, Friedman R, Canani LH. Nitric oxide system and diabetic nephropathy. Diabetol Metab Syndr 2014;6:17.

20. Galecki P, Maes M, Florkowski A, et al. Association between inducible and neuronal nitric oxide synthase polymorphisms and recurrent depressive disorder. J Affect Disord 2011;129:175-182.

21. Munshi A, Rajeshwar K, Kaul S, et al. VNTR polymorphism in intron 4 of the eNOS gene and the risk of ischemic stroke in a South Indian population. Brain Res Bull 2010;82:247-250.

22. Wang XL, Mahaney MC, Sim AS, et al. Genetic contribution of the endothelial constitutive nitric oxide synthase gene to plasma nitric oxide levels. Arterioscler Thromb Vasc Biol 1997;17:3147-3153.

23. Levecque C, Elbaz A, Clavel J, et al. Association between Parkinson's disease and polymorphisms in the nNOS and iNOS genes in a community-based case-control study. Hum Mol Genet 2003;12:79-86.

24. Vigo AG, Martinez A, de la Concha EG, Urcelay E, Ruiz de León A. Suggested association of NOS2A polymorphism in idiopathic achalasia: no evidence in a large case-control study. Am J Gastroenterol 2009;104:1326-1327.

25. Sadowski DC, Ackah F, Jiang B, Svenson LW. Achalasia: incidence, prevalence and survival. A population-based study. Neurogastroenterol Motil 2010;22:e256-e261.

26. Ghoshal UC, Singh R, Misra A. Esophageal function tests in clinical practice: a review. Trop Gastroenterol 2010;31:145-154.

27. Bredenoord AJ, Fox M, Kahrilas PJ, et al. Chicago classification criteria of esophageal motility disorders defined in high resolution esophageal pressure topography. Neurogastroenterol Motil 2012; 24(suppl 1):57-65.

28. Pratap N, Kalapala R, Darisetty S, et al. Achalasia cardia subtyping by high-resolution manometry predicts the therapeutic outcome of pneumatic balloon dilatation. J Neurogastroenterol Motil 2011;17: 48-53.

29. Misra A, Chourasia D, Ghoshal UC. Manometric and symptomatic spectrum of motor dysphagia in a tertiary referral center in northern India. Indian J Gastroenterol 2010;29:12-16.

30. Pandolfino JE, Kwiatek MA, Nealis T, Bulsiewicz W, Post J, Kahrilas PJ. Achalasia: a new clinically relevant classification by high-resolution manometry. Gastroenterology 2008;135:1526-1533.

31. Lin Z, Kahrilas PJ, Roman S, Boris L, Carlson D, Pandolfino JE. Refining the criterion for an abnormal Integrated Relaxation Pressure in esophageal pressure topography based on the pattern of esophageal contractility using a classification and regression tree model. Neurogastroenterol Motil 2012;24:e356-e363.
32. Longstreth GF, Thompson WG, Chey WD, Houghton LA, Mearin F, Spiller RC. Functional bowel disorders. Gastroenterology 2006;130:1480-1491.

33. Park SY, Rew JS. A patient with progression of diffuse esophageal spasm to classic achalasia. J Neurogastroenterol Motil 2012;18: 100-101.

34. Murray JA, Ledlow A, Launspach J, Evans D, Loveday M, Conklin JL. The effects of recombinant human hemoglobin on esophageal motor functions in humans. Gastroenterology 1995;109: 1241-1248.

35. Hornby PJ, Abrahams TP. Central control of lower esophageal sphincter relaxation. Am J Med 2000;108(suppl 4a):90S-98S.

36. Sivarao DV, Mashimo HL, Thatte HS, Goyal RK. Lower esophageal sphincter is achalasic in $\mathrm{nNOS}^{-/-}$and hypotensive in $\mathrm{W} / \mathrm{W}^{\mathrm{v}}$ mutant mice. Gastroenterology 2001;121:34-42.

37. Rivera LR, Poole DP, Thacker M, Furness JB. The involvement of nitric oxide synthase neurons in enteric neuropathies. Neurogastroenterol Motil 2011;23:980-988.

38. Borroni B, Rao R, Liberini P, et al. Endothelial nitric oxide synthase (Glu298Asp) polymorphism is an independent risk factor for migraine with aura. Headache 2006;46:1575-1579.

39. Qualman SJ, Haupt HM, Yang P, Hamilton SR. Esophageal Lewy bodies associated with ganglion cell loss in achalasia. Similarity to Parkinson's disease. Gastroenterology 1984;87:848-856.

40. Kim CD, Goyal RK, Mashimo H. Neuronal NOS provides nitrergic inhibitory neurotransmitter in mouse lower esophageal sphincter. Am J Physiol 1999;277(2 Pt 1):G280-G284.

41. Marian AJ. Molecular genetic studies of complex phenotypes. Transl Res 2012;159:64-79.

42. Grasemann H, Yandava CN, Drazen JM. Neuronal NO synthase (NOS1) is a major candidate gene for asthma. Clin Exp Allergy 1999;29(suppl 4):39-41.

43. Chabrier PE, Demerlé-Pallardy C, Auguet M. Nitric oxide synthases: targets for therapeutic strategies in neurological diseases. Cell Mol Life Sci 1999;5 5:1029-1035.

44. Ripplinger J. [Investigations on the pneumogastric of the tench; the behavior of chronotropic and tonotropic fibers during wallerian degeneration of the vagal trunk]. J Physiol 1952;44:316-319.

45. Diaz-Corrales FJ, Asanuma M, Miyazaki I, Miyoshi K, Ogawa N. Rotenone induces aggregation of gamma-tubulin protein and subsequent disorganization of the centrosome: relevance to formation of inclusion bodies and neurodegeneration. Neuroscience 2005;133: 117-135.

46. Paranjape SA, Briski KP. Recurrent insulin-induced hypoglycemia causes site-specific patterns of habituation or amplification of CNS neuronal genomic activation. Neuroscience 2005;130:957-970.

47. Paladini F, Cocco E, Cascino I, et al. Age-dependent association of idiopathic achalasia with vasoactive intestinal peptide receptor 1 gene. Neurogastroenterol Motil 2009;21:597-602.

48. Bak YT, Lorang M, Evans PR, Kellow JE, Jones MP, Smith RC. Predictive value of symptom profiles in patients with suspected oesophageal dysmotility. Scand J Gastroenterol 1994;29:392-397. 